\title{
Choice of Adaptation Strategies to Climate Variability among Smallholder Farmers in the Maize Based Cropping System in Namutumba District, Uganda
}

\author{
Bul John Ajak ${ }^{*}$, Florence Birungi Kyazze', Paul Isolo Mukwaya² \\ ${ }^{1}$ Department of Extension and Innovation Studies, College of Agricultural and Environmental Sciences, \\ Makerere University, Kampala, Uganda \\ ${ }^{2}$ Department of Geography, Geo-Informatics and Climatic Sciences, School of Forestry, Environment and Geographical \\ Sciences, College of Agricultural and Environmental Sciences, Makerere University, Kampala, Uganda \\ Email: ^buljohn ajak70@gmail.com
}

How to cite this paper: Ajak, B.J., Kyazze, F.B. and Mukwaya, P.I. (2018) Choice of Adaptation Strategies to Climate Variability among Smallholder Farmers in the Maize Based Cropping System in Namutumba District, Uganda. American Journal of Climate Change, 7, 431-451. https://doi.org/10.4236/ajcc.2018.73026

Received: March, 6, 2018

Accepted: August 21, 2018

Published: August 24, 2018

Copyright $\odot 2018$ by authors and Scientific Research Publishing Inc. This work is licensed under the Creative Commons Attribution International License (CC BY 4.0).

http://creativecommons.org/licenses/by/4.0/

\begin{abstract}
Smallholder farmers in Namutumba district draw on a combination of adaptation strategies to respond to effects of climate variability. However, there is limited scholarly evidence and explanation that has been conducted on the factors that influence the choice of alternative sets of strategies that smallholder farmers use in response to climate variability specific stress and literature that disentangles climatic stressors specific adaptation options. A multi-stage sampling procedure was employed to select the study area and household respondents. The study used cross-sectional research design to collect both quantitative and qualitative data. Household data was collected from 160 respondents with a structured questionnaire supported by key informant interviews. Multinomial logit modeling (MNL) was used to determine the relative influence of selected household socio-demographic factors on the choice of adaptation strategies against the dry spell. Principal Components Analysis (PCA) was used to create weighted adaptation index for categorizing various similar adaptation strategies. In order to respond to the impact of climate variability stresses, smallholder farmers have adapted growing drought-resistant crops (12.2\%), extension of the agricultural frontier into wetlands during the dry spells (37\%), whereas use of crop rotation (9.8\%) is the most dominant strategies used to manage pest and diseases, similarly soil and water conservation (15.3\%) and climate-smart planning basin (11\%) are the most dominant adaptation strategies use to manage flood. Empirical results from multinomial logit modeling showed that predictor variables gend-
\end{abstract}


er, level of education, years of farming, house size, access to credit, and own radio have a significant influence on the choice of adaptation strategies with differences significant level during the dry spell. The study recommends that future policies should focus on strengthening the existing extension training package, strengthening the existing farmer's groups and cooperatives, encouraging informal social networks in order to boost smallholder farmers' adaptation to climate variability.

\section{Keywords}

Choice, Climate Variability, Smallholder Farmers, Adaptation Strategies, Dry Spell and Namutumba

\section{Introduction}

The climate has changed, is changing, and will continue to change regardless of what investments in it mitigation are made [1]. As a result of climate change atmosphere and oceans have warmed, sea levels have risen and glaciers and ice sheets have decreased in size. This has been mainly caused by greenhouse gas emissions from human activities. This, in turn, has had tremendous effects on ecosystems, coastal systems, fire regimes, food and water security, health, infrastructure and human security [2]. With climate change, new occurrences with some seasons being drier than others, having more precipitations than others and having higher temperatures than others have appeared causing climate variability.

Like in the other sub-Saharan countries, most smallholder farmers households in Uganda depend on cereals (most especially, maize) as a contributing; if not principal, the source of food and nutrition [3]. Maize is one of the important grains in eastern Uganda as well as in Namutumba district, not only on the basis of the number of farmers that engaged in its cultivation but also in its economic value. Despite its high yield potential, maize production is however confronted with several bottlenecks. One of the major constraints is recurrent dry spell and flooding during the growing season, which, significantly reduce maize yield [4]. Also, climate variability presents many constraints among smallholder farmers in Uganda because of the increase in temperature which reduces moisture in the soil in addition to the increased variability in rainfall for most parts of Uganda [5]. Uganda particularly Namutumba district is already vulnerable to extremes climatic variability; and climate variability is likely to increase the frequency and magnitude of some natural hazards and extreme weather events [6]. These extreme events could be worsened by existing institutional, economic and social challenges in the region, particularly for those areas and communities depending on resources that are sensitive to climate variability [7]. This is expected to pose a huge threat to smallholder farmers in most district of eastern Uganda due to their overwhelming reliance on small-scale farming [8] [9].

There are however several efforts by smallholder farmers to reduce climate 
variability challenges by adapting to strategies that include but are not limited to sharing of indigenous and improved technological knowledge on crop diversification, switching crops, irrigation, crop rotation, mulching, integrated pest management, agroforestry systems, water and soil conservation, better crop management and use of improved crop varieties among others [10] [11]. While this is true, little empirical evidence exists to substantiate the context that guides the farmer's choices of one strategy or package of strategies to employ in their effort to reduce climate variability related challenges. In this regard, the context including the, socio-economic, farmers' institutional arrangement on land, climatic variables, actors' interaction mechanism and information flows system that work in unison or independently to inform farmers' choice of adaptation strategies to climate variability form the core reason of this study. Therefore the objective of this study was 1) To identify and characterize adaptation strategies employed by smallholder farmers to manage climate variability stresses; 2) To determine the factors that influence smallholder farmers' choice of alternative sets and combinations of adaptation strategies to climate variability in Namutumba district.

\section{Materials and Methods}

\subsection{Study Area}

The study was conducted in Magada, Bulange, Namutumba, and Ivukula Sub County of Namutumba district as show in Figure 1. The district is located in southeastern Uganda; approximately $152 \mathrm{~km}$ (94.00 miles) from Kampala city; the main administrative capital of Uganda. Namutumba district geographically lies between Latitudes $00^{\circ} 50^{\prime} 06^{\prime \prime} \mathrm{N}$ and Longitudes $33^{\circ} 41^{\prime} 06^{\prime \prime} \mathrm{E}$. The total area covered by the district is $801.87 \mathrm{sq} \cdot \mathrm{km}$ most of which is land. Namutumba district was selected owing to its fragility and sensitivity to climate variability incident. For instance, the districts experience the occurrence of climatic events such as droughts and floods in 2010 and 2012 respectively leading to severe socio-economic impacts that included food insecurity, crop diseases, pests and as well as yield losses.

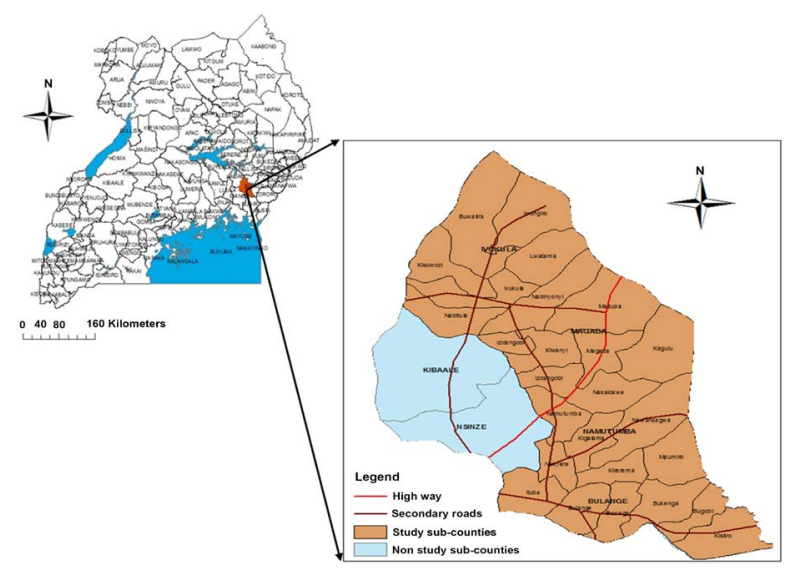

Figure 1. Namutumba district in eastern Uganda. 


\subsection{Design and Sampling Techniques}

By considering the time and logistic constraints into account the study employed a cross-sectional survey research design in order to assess the overall activities at one shot as described by [12]. The design captures a sample of the population as representative of the population and it is easy to use for descriptive and empirical studies. In this study, the researcher employed both purposive and random sampling technique for selecting study area and sampled farmers' households, respectively. First the region and the district was selected purposively considering the fact that it is one of the most vulnerable areas to the impacts of climate change in eastern Uganda, which is evidenced by the 2010 floods and drought according to environmental alert-Uganda working report [13] and due to it fragility and sensitivity to climate variability [14].

Secondly, four sub-counties were selected district based on the fact that they were identified the most vulnerable counties to the impacts of climate variability in Namutumba district. Two parishes were selected from each sub-county making a total of 8 parishes in all the 4 sub-counties, also purposively, basing on information that was obtained from the local leaders regarding the parishes that have suffered more from climatic shocks like floods and drought in the last ten years. From each of the 8 parishes, two villages were selected randomly from each of the parishes to make a total of 16 villages due to their agricultural production potential. Then a sample of households was selected from each of the 16 villages using proportionality sampling to the size of the population.

\subsection{Data Sources and Collection}

In this study, both qualitative and quantitative data from primary and secondary sources were used. Primary data were collected from the sampled respondents on different issues such as household characteristics observed changed in climate variability stresses, adaptation strategies employed to deal with specific climate variability stress and all other variables hypothesized to influence the choice of adaptation strategies. To have detailed information useful to draw the right conclusion from the survey exercise, qualitative information was also gathered through holding focus group discussion with smallholder farmers from the samples study area. In addition, secondary data were collected from records from different stakeholders particularly the district agricultural offices, and related literature prepared by the government and nongovernmental organization.

A household survey was conducted to assess the adaptation strategies employed by smallholder farmers' households to the consequences of climate variability stressors. A structured household survey questionnaire was used to carry out household interviews. For a better understanding and facilitation process, the schedule was translated into Lusoga language. Firstly, the household questionnaires were pre-tested before actual data collection at the farm level on 10 randomly selected non-sample households to check their reliability and validity 
before the ready data collection, this actual help to avoid the ambiguity of some of the questionnaire items. The modification was made to amend some of the questions to make them fit to the context. Training was given for the selected 5 enumerators on the contents of the interview questionnaires and methodology to approach farmers. The survey was conducted under the close supervision and full participation of the researcher. The data collected through household survey were cross-checked with systematic focus group discussion and direct observation aimed at getting a holistic picture of the adaptation strategies of smallholder farmers to climate variability in the area. Household semi-structured questionnaire and interview were employed to determine farmers' choice factors that influence of adaptation option to climate variability. A structured household interview was used to collect the socio-economic data of the study. The data that was obtained by this method include demographic characteristics of households, farmer's choice and the decision of adaptation strategies to climate shocks. Structured household interviews were administered to the target respondents using a questionnaire.

\subsection{Data Analysis Method}

\subsubsection{Modeling Choice of Adaptation Strategies to Climate Variability Stresses}

To run the multinomial logit model principal component analysis (PCA) was used to reduce the obtained large numbers of adaptation strategies that are correlated with one another and response to the same construct into smaller number of categorized adaptation strategies that will account for most of the variance in the reported adaptation strategies which are used in Multinomial logit.

One of the underlying motivations for the household choice of alternative adaptation strategies to climate variability stresses is to maximize utility from expected earnings from a particular strategy [15]. Thus, smallholder farmer choice of which adaptation strategy to engage in can be based on the random utility framework as specified by [16]. The random utility model (RUM) postulates that farmer choice of different adaptation strategies is geared towards maximizing its utility. I specify a common formulation of linear random utility model as;

$$
U_{i j}=\beta_{j} X_{i j}+\varepsilon_{i j}
$$

where: $I=1, \cdots, N$ are the individual smallholder farmer and $j=1, \cdots, J$ are the Alternative adaptation strategies.

$X_{i j}$ vectors $=$ the factors that influence smallholder farmers' choice of adaptation practices to climate variability and $\varepsilon_{i j}$ is the random error term. In this model, we guess that smallholder farmers are rational decision makers who maximize the utility from adaptation practices in their farming activities and also predict that farmers face climatic related stresses in their farming activities will look for adaptation practices. If farmer $i$ make choice $j$ adaptation, in particular, we assume that $U_{i j}$ is the maximum utility among the $J$ adaptation strategies.

Prob $\left(U_{i j}>U_{i k}\right) \ldots$ for all other $k \neq j$, the probability of smallholder farmer 
chooses a particular alternative $j$ is given by the probability that the utility of that alternative to the farmer is greater than the utility to that farmer of all other alternative $J$.

This study used the multinomial logit (MNL) model to analyze the factors that driver smallholder farmer choice adaptation strategies because it is widely used in studies involving multiple choices and is easier to compute than multinomial probit (MNP). The merit of using MNL model is its simplicity in calculating the choice probabilities that are expressible in analytical form. The MNL model was used by many researchers to model climate change adaptation of smallholder farmers [17]. Therefore, this study used multinomial logit model choice of climate variability adaptation strategies because MNL model for choice of adaptation strategies specifies the relationship between the probability of choosing an adaptation strategy and the set of predictor variables.

To describe the multinomial logit model, let $Y$ denoted a vector of adaptation strategies for climate variability to chosen by smallholder farmer. Assuming the adaptation method farmers' choice depends on the socioeconomic characteristic of the farmers' and access to informal and formal institutions. The Multinomial logit model for the adaptation choice can be specified as a relationship between the probability of choosing a practice and a set of explanatory variables $X$ [18].

$$
\operatorname{Prob}(Y i=j)=\frac{e \beta j \times i}{1+\sum_{k}^{5} e \beta K x i}, \quad j=0,1,2 \cdots 18
$$

Equation (1) is normalized to remove indeterminacy in the model by assuming $=0$ and the probabilities can be estimated as:

$$
\operatorname{Prob}(Y i=j / x i)=\frac{e \beta j \times i}{1+\sum_{k=0}^{j} e \beta K x i}, j=0,1,2 \cdots J, \quad \beta_{0}=0
$$

Maximum likelihood estimates of Equation (2) yield the log-odds ratio

$$
\operatorname{Ln}\left(\frac{\delta P_{j}}{P_{i k}}\right)=x_{i},\left(\beta_{i}-\beta_{k}\right)=X_{i}-\beta_{j}, \quad \text { if }=0
$$

The dependent variable of any adaptation strategies is, therefore, the log of odd in relation to the base categories.

According to [19], the MNL coefficients are difficult to interpret and associating with the th outcome is tempting. Marginal effect is use to interpret the effect of independent variable on the dependent variable in terms of probabilities.

$$
\frac{\delta P_{j}}{\delta x_{i}}=P_{j}\left(\beta_{\mathrm{i}}-\sum_{k=0}^{j} P_{K} \beta_{j}\right)=P_{j}\left(\beta_{j-\beta}\right)
$$

The marginal effects, measure the expected change in the probability of a particular choice being made with respect to a unite change in the explanatory variable [20]. The weighted adaptation index was created using Principal Component Analysis (PCA) based on the number of adaptation strategies smallholder farmers choose against each of the climate variability stresses to extract one or 
more linear combinations of adaptation strategies. [21] stated that principal component analysis is used to assign weights single variables in order to generate a combination of a similar variable. Therefore, the principal component analysis is used in this study as to identify similarities in the adaptation strategies for easy categorization. Using the weighted index from the principal component analysis the adaptation strategies for each climatic stress were categorized into the following categories. Dry spell adaptation strategies were categorized into 5, as soil and water conservation, diversify multiples occupation, changing crop calendar, cultivating in wetland and no adaptation.

\subsubsection{Model Specification}

To achieve the second objective on the factors that influence the choice of adaptation strategies by smallholder farmers in study area, the structural form was reduced and the variable fitting in the model as:; $Y i=\beta_{0}+\beta_{1}$ gender $+\beta_{2}$ marital status $+\beta_{3}$ level of education $+\beta_{5}$ year of farming $+\beta_{6}$ household size $+\beta_{7}$ land size $+\beta_{8}$ area under crops $+\beta_{9}$ access to extension $+\beta_{10}$ credit $+\beta_{11}$ belong to groups $+\beta_{12}$ land tenure $+\beta_{14}$ income $+\beta_{15}$ own radio $+\beta_{16}$ information $+\beta_{17}$ training on climate adaptation $+e_{i}$, where $Y i$ is the number of adaptation strategies smallholder farmer was involved in the explanatory variables.

\section{Results and Discussions}

\subsection{Adaptation Strategies Used by Smallholder Farmers in Managing Climate Stresses in Namutumba District}

Smallholder farmers who observed the existence of climate variability had suitably choice and implement one or more adaptation strategies as means to reduce the adverse effects of the climate variability stresses. Results from household survey indicate that smallholder farmers have choice and employed ranges of long-term and short-term adaptation strategies, some of which are inward and outward-looking and might require financial or non-financial resources in order to deal with specific climatic stress such as dry spell, floods, heavy rain, pest and diseases, occurrence of hailstorm in the study area as presented in Table 1. As one farmer in Magada Sub County explained during the focus group discussion (FGDs) that, "we are dependent on the rains from God, and there is no alternative for us to change these weather patterns", smallholder farm embark on the extension of agricultural frontier into wetlands during the long dry spells (37\%) while some smallholder farmers have built water harvesting structure such as dug water ponds to store excess rainwater and use it during dry spell, but this types of water harvest has only occurred on a very small scale. Results in Table 1 indicated that $34.5 \%$ of the farmers' interview are employed micro irrigation during dry spell. In addition to dug water harvest ponds, other potential adaptation strategies discussed during the focus group include the use of large containers to store rainwater, but again, the lack of capital prevented most households from using these strategies. 
Table 1. Adaptation strategies used by smallholder farmers to deal with climate variability stresses.

\begin{tabular}{|c|c|c|c|c|}
\hline \multirow[b]{2}{*}{ Adaptation strategies } & \multicolumn{4}{|c|}{ Percent responses to climatic stresses } \\
\hline & $\begin{array}{c}\text { Dry } \\
\text { spells }\end{array}$ & Flood & $\begin{array}{c}\text { Pest and } \\
\text { disease }\end{array}$ & Heavy rains \\
\hline Building water harvesting structures & 33.8 & 6.9 & 0 & 8.8 \\
\hline Building soil and water conservation & 26.3 & 42.5 & 0 & 40 \\
\hline Introduce micro-irrigation & 34.5 & 0 & 0 & 0 \\
\hline Growing early maturing crop varieties & 67.5 & 24.4 & 52.5 & 22.5 \\
\hline Use improve seed & 0 & 0 & 60.6 & 0 \\
\hline Growing drought-resistant crop varieties & 81.3 & 0 & 29.4 & 0 \\
\hline Use crop rotation & 0 & 1.3 & 83.1 & 5 \\
\hline Use inter-cropping & 0 & 1.3 & 68.1 & 9.4 \\
\hline Use mixed farming & 64.8 & 30 & 63.8 & 34.4 \\
\hline Change crop calendar & 56.9 & 12 & 29.4 & 21.3 \\
\hline Mulching & 0.1 & 28.1 & 3.75 & 21.9 \\
\hline Use cover crop & 0.2 & 13.1 & 14.4 & 8.8 \\
\hline Use of grass strip & 0 & 10.6 & 0.63 & 9.4 \\
\hline Temporary migration & 0 & 0 & 0 & 4.4 \\
\hline Engaged in off-farm business & 67.5 & 25.6 & 43.8 & 40 \\
\hline Sale of labor to another farm & 19.4 & 4.38 & 8.13 & 33.8 \\
\hline Growing food security crop & 76.9 & 21.9 & 39.4 & 38.1 \\
\hline Use of granary & 5 & 5.63 & 10.6 & 7.5 \\
\hline Use of silos/cribs & 3.75 & 0.63 & 1.88 & 0 \\
\hline Earlier land preparation & 59.4 & 8.13 & 43.9 & 15.6 \\
\hline Climate-smart planting basins & 17.5 & 28.8 & 6.25 & 33.1 \\
\hline Cultivate in wetland & 37 & 1.88 & 0 & 23 \\
\hline Rearing livestock & 58.1 & 20.6 & 45.6 & 26.9 \\
\hline
\end{tabular}

Source: Computed from field survey data, 2016 (multiple responses).

Smallholder farmers also reported the growing of drought tolerant crop varieties, such as cassava. By far, the most effective long-term adaptation strategy employed by farmers is to diversify their income include engaging off-farm activities during dry spell. The farmers during FGDs reported that when you extensively engaged in off-farm activities, such as wage-earning jobs, owning small shops, or selling livestock, you have a better chance to deals with climate-related stresses than their farming neighbors. The farmers were more hesitant to practices mixed farming order to adapt to the unexpected occurrence of a dry spell. This finding agrees with the current discussion about crop diversity in which most smallholder farmers are interested in changing their cropping practices to better suit the current, drier, weather conditions [22]. The farmer in the study area has considered diversifying crop varieties as an option to deal with weather variation.

Adaptation strategies employed by smallholder farmers during floods include building soil and water conservation structures (42.5\%) and water harvesting structures (6.9\%) for example building trenches and reservoirs to divert and 
store runoff water. During the focus group discussion (FGDs) farmers reported building trenches but due to the labor requirements, people only built trenches to protect those areas under crop and home. Many smallholder farmers would like to expand these trench practices to better manage with future floods. One farmer in Madaga Sub County also constructed pools and canals to divert and hold the excess water, but due to the local traditional techniques of construction, these reservoirs usually broke down during heavy rains.

Smallholder farmers reported the use of climate-smart planting basin (Figure 2) to reduce soil erosion by slowing water velocity as some adaptation strategies during both heavy rain (33.1\%) and flood (6.3\%). During the focus group discussion (FGDs) farmers reported that trees are helpful because, according to one farmer, "Tree help keeps the soil in one place". Even farmers who had not been involved in climate-smart agriculture cited the important of using trees to reduce their exposure to floods and heavy rain. Smallholder Farmers in study area also reported that trees help them deal with the dry spell, as they found that selling tree crops, like fuel wood and fruit, during times when other crops had failed provided them with additional income to purchase other food and cope with the situation.
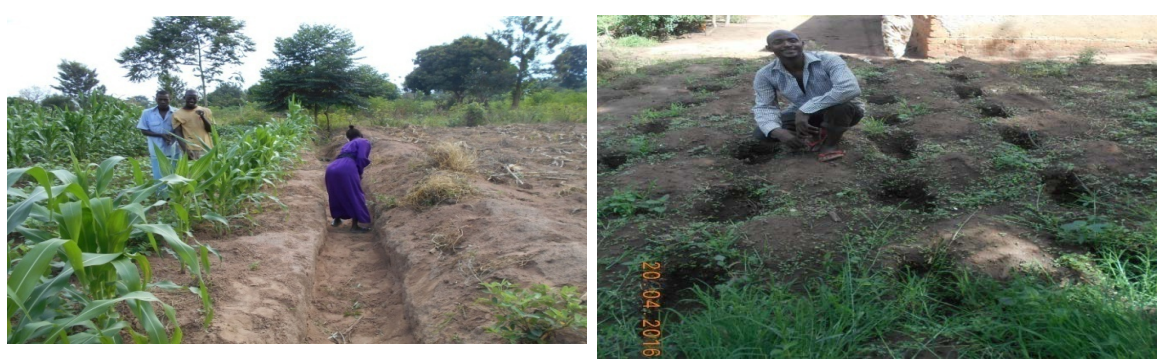

Figure 2. One of the selected farmers employing climate-smart planting basins in Magada.

This finding agrees with much of the adaptation strategies literature echoed in Uganda by smallholder farmers in the effort to deal with climate variability-related stresses [23] [24].

Smallholder farmers were also asked to mention the adaptation strategies they use dealing pests and diseases incidences. The results show that the use of crop rotation $(83.1 \%)$ emerged as the most used adaptation practices against pests and diseases and the use of intercropping, mulching, abandon the growing of some crops which are easily susceptible pest and disease attacked were some of the practices employed in the area. All these methods are known as integrated pest management that involves the use of different methods in managing pests and disease in crops at a given time. During focus groups discussion with farmers, harvested cereals are also preserved by keeping them above fire places in specially made stores known as Ekyaagi in Lusoga. Farmers, however, acknowledged that cereals stored still get infested by pests. They are not aware of the correct heap width and even for how long the Ekyaagi can be effective, leave alone the amount of heat needed. 


\subsection{Multiples Adaptation Strategies Categorization Using Principal Component Analysis}

As noticed earlier, the majority of the smallholder farmers who choice adaptation strategies engage in multiple combinations of adaptation strategies in response to specific stress. Therefore, in this study, the identified adaptation strategies choose by smallholder farmers in response to climatic stresses were combined into categories with respect to each stress for the convenience of model's analysis and because of their close relationship. They identify adaptation strategies were attached weight using principal component analysis (PCA). PCA is fundamentally a dimension reduction technique for multivariate data analysis, according to [25]. The first principal component defines the linear index of all the variables from a set of variables which captures the largest amount of information common to all the variables. This will help to capture the highest variability in the data. Furthermore, the heaviest loading of principal component expressed in terms of the variables is an index for each household which will capture the largest amount of information. From the principal component analysis, different principal components were extracted cross all the climate variability stresses as presented in Table 2.

Table 2. Showing adaptation strategies used during dry spell and the extracted components.

\begin{tabular}{|c|c|c|c|c|c|}
\hline \multirow{2}{*}{$\begin{array}{l}\text { Adaptation strategies used } \\
\text { during dry spell }\end{array}$} & \multicolumn{4}{|c|}{ Rotated component } & \multirow{2}{*}{ Categorization } \\
\hline & 1 & 2 & 3 & 4 & \\
\hline Soil and water conservation structures & $0.804^{*}$ & & & & Soil and water \\
\hline Water harvesting structures & $0.782^{*}$ & & & & conservation \\
\hline Micro-irrigation & $0.560^{*}$ & & & & techniques \\
\hline Mixed farming & & $0.797^{*}$ & & & \\
\hline Rearing livestock & & $0.681^{*}$ & & & \\
\hline Engaging in off-farm business & & $0.605^{*}$ & & & Diversify multiple \\
\hline Growing Early maturing crop varieties & & $0.797^{*}$ & & & occupations \\
\hline Drought resistant crop varieties & & $0.649^{*}$ & & & \\
\hline Improved seeds & & $0.534^{*}$ & & & \\
\hline Changing crop calendar & & & $0.880^{*}$ & & Changing crop \\
\hline Abandon growing some crops & & & $0.765^{*}$ & & calendar \\
\hline Cultivating wetland & & & & $-0.718^{*}$ & Cultivating in \\
\hline Growing food security crops & & & & $0.728^{*}$ & wetland \\
\hline
\end{tabular}

Notes: Rotation method: varimax with Kaiser normalization. ${ }^{*}$ is variable loadings.

\subsection{Multinomial Logit Regression Model Results and Discussions}

Before running the model, different tests which are very essential for multinomial logit model were undertaken. The Multinomial logit model was em- 
ployed to determine the factors that influence smallholder farmers' choice of adaptation strategy to climate variability stresses with 21 explanatory variables. The model was fitted into STATA version 12 and tested for multicollinearity. The existence of multicollinearity between the explanatory variable was checked using Variance Inflating Factor (VIF) and correlation matrix methods prior to running the final regression analysis. The results of the test indicate the presence of no severe problem of multicollinearity among the explanatory variables. The rule of thumb for interpreting is that the variance inflation factor should be between 0 and 1 . If the VIF is equal to 1 there is no problem of multicollinearity among independent variables, but if the Variance Inflation Factor (VIF) is more than 1, the independent variables might be moderately correlated. A VIF between 5 and 10 specifies high correlation that could be complex [16]. And if the variance inflation factor goes above 10 , it can be assumed that the regression coefficients are poorly estimated due to multicollinearity which can be addressed by removing highly correlated independent variables from the model to ensure noreduction in the precision of the parameter estimate in the multinomial logit model. The results of the test indicate the presence of no severe problem of multicollinearity among the explanatory variables. Since the VIF for each explanatory variable is less than 2 with a mean of 1.45 for each of the explanatory variable which indicates that no problem of multicollinearity was detected as in Table 3.

Therefore the use of the MNL model description was found to be suitable, and model has been used previously by different scholars [20] [34] [29] to estimate the decision for the adoption of climate change adaptation technologies by farmers.

\section{Factors That Influencing the Choice of Adaptation Strategies} during the Dry Spell

In this subsection, Table 4 and Table 5 provide the results on factors influencing smallholder farmers' choice of actual adaptation strategies in response to climate variability stresses. Farmers in Namutumba district observed six climate variability stresses; however, for this subsection we will take dry spell because it's the most occurring stress for analysis. The model constructed is based on the factors that determine the choice of different adaptation strategies during the dry spell. It is also essential to note that smallholder farmers used different adaptation strategies to respond to dry spell in the study area.

The Multinomial Logit Model was run taking "No adaptation options" as the base category against which the remaining outcomes are compared with. Given the argument from the literature that parameter estimates of the multinomial logit model provide only the direction of the effect of the independent variable on the dependent variable. Then we go further to compute the magnitude of effect by using strata command margins, $\operatorname{dydx}\left({ }^{*}\right)$ pre (out $\left({ }^{*}\right)$ ) after multinomial logit model by computed the marginal effect for the ease of interpretation, for each outcome in the dependent variable. In the context of this research the marginal 
Table 3. The variance inflation factors for multinomial logit model.

\begin{tabular}{ccc}
\hline Variable & VIF & $1 /$ VIF \\
\hline Marital & 1.87 & 0.482878 \\
Area under crop & 1.74 & 0.582912 \\
Age & 1.68 & 0.581335 \\
Access to extension & 1.66 & 0.667802 \\
Access to training & 1.50 & 0.679056 \\
Years of farming & 1.58 & 0.69862 \\
Level of education & 1.43 & 0.712606 \\
Household size & 1.41 & 0.720076 \\
HHs income & 1.49 & 0.739874 \\
Land size & 1.35 & 0.759503 \\
Land tenure & 1.31 & 0.772303 \\
Gender & 1.28 & 0.827789 \\
Belonging to a group & 1.14 & 0.840883 \\
Access to credit & 1.11 & 0.848579 \\
Own radio & 1.11 & 0.945426 \\
& Mean VIF 1.45 & \\
\hline
\end{tabular}

Source: own survey results, 2016.

effects refer to change in probability of a particular choice of adaptation strategiesagainst climate variability stresses for a unit change in the explanatory variables. Therefore, MNL model was run based on one the of most occurring climate variability stress, that is, dry spell.

The hypothesized explanatory variables were entered into Multinomial logit model (MNL) to see their individual and aggregate influence on the choice of adaptation strategies in response to a dry spell in Namutumba district. As the results indicate clearly in Table 4, the probability of chi-square shows that likelihood ratio statistics are highly significant at $p<0.0000$, suggesting that the model has a strong explanatory power. Also, the model has a pseudo $\mathrm{R}^{2}$ of 0.3397 which means that $33.97 \%$ of the variation in the dependent variable is due to the variations in the independent variables and that confirming households' choice of adaptation strategies could be attributed to fitted covariates, the $\mathrm{R}^{2}$ measure of goodness of fit and therefore the model appeared to have performed very well. The parameter estimates of the MNL model was used to provide the direction of the effect of the independent variables on the response variable, where parameter estimates represent neither the actual magnitude of change nor the probabilities.

As mention earlier, the parameter estimates of the MNL model provide only the direction of the effect of the explanatory variables on the response variable: parameter estimates do not denote actual magnitude of change or probabilities. 
Table 4. Parameter estimates of the multinomial logit climate change adaptation model.

\begin{tabular}{|c|c|c|c|c|}
\hline $\begin{array}{c}\text { Explanatory } \\
\text { variable }\end{array}$ & $\begin{array}{c}\text { Soil and water } \\
\text { conservation } \\
\text { Coef. } \\
\text { p-value }\end{array}$ & $\begin{array}{l}\text { Diversify multiples } \\
\text { occupation } \\
\text { Coef. } \\
\text { p-value }\end{array}$ & $\begin{array}{l}\text { Changing crop } \\
\text { Calendar } \\
\text { Coef. } \\
\text { p-value }\end{array}$ & $\begin{array}{c}\text { Cultivating } \\
\text { in wetland } \\
\text { Coef. } \\
\text { p-value }\end{array}$ \\
\hline \multirow{2}{*}{ Gender } & 0.911 & 0.356 & 0.998 & 1.576 \\
\hline & $0.096^{*}$ & $0.057^{\star *}$ & 0.393 & 0.168 \\
\hline \multirow{2}{*}{ Age of $\mathrm{HHs}$} & -0.0 .13 & -6.459 & -4.466 & -4.799 \\
\hline & $0.019^{* *}$ & 0.111 & 0.269 & 0.232 \\
\hline \multirow{2}{*}{ Marital status } & -1.402 & -0.199 & -2.851 & -3.997 \\
\hline & $0.028^{\star *}$ & 0.856 & $0.056^{\star *}$ & $0.008^{\star * *}$ \\
\hline \multirow{2}{*}{ Level-education } & 1.751 & $0.042^{* *}$ & -0.951 & -1.520 \\
\hline & $0.001^{* * *}$ & 0.581 & 0.397 & 0.151 \\
\hline \multirow{2}{*}{ Years farming } & 0.042 & 1.300 & .1385 & 0.025 \\
\hline & 0.581 & 0.199 & 0.505 & 0.736 \\
\hline \multirow{2}{*}{ Household size } & 0.159 & -2.008 & 0.030 & 0.216 \\
\hline & $0.057^{\star *}$ & $0.069^{\star *}$ & 0.687 & 0.827 \\
\hline \multirow{2}{*}{ Land size } & 0.820 & 3.650 & 0.404 & -2.790 \\
\hline & 0.283 & $0.053^{* *}$ & 0.691 & 0.213 \\
\hline \multirow{2}{*}{ Area under crop } & 2.519 & -6.139 & -2.300 & 5.210 \\
\hline & 0.338 & $0.002^{\star * *}$ & 0.304 & $0.045^{\star *}$ \\
\hline \multirow{2}{*}{ HHs income } & -1.088 & 5.538 & 4.283 & -4.602 \\
\hline & $0.013^{* *}$ & $0.003^{* * *}$ & $0.005^{\star * *}$ & $0.021^{* *}$ \\
\hline \multirow{2}{*}{ Belong to group } & 1.132 & -2.811 & 5.815 & 5.474 \\
\hline & $0.005^{\star * *}$ & $0.044^{* *}$ & $0.002^{* * *}$ & $0.003^{* * *}$ \\
\hline \multirow{2}{*}{ Land tenure } & -2.768 & -0.873 & -3.462 & -4.261 \\
\hline & $0.052^{* \star}$ & 0.560 & $0.018^{* *}$ & $0.003^{\star * \star *}$ \\
\hline \multirow{2}{*}{ Access to credit } & -3.230 & 4.152 & -0.696 & -1.303 \\
\hline & $0.028^{\star *}$ & 0.560 & 0.646 & 0.372 \\
\hline \multirow{2}{*}{ Access extension } & 1.516 & -1.417 & 3.629 & 3.395 \\
\hline & $0.048^{* *}$ & 0.600 & 0.174 & 0.202 \\
\hline \multirow{2}{*}{$\begin{array}{l}\text { Access to climate } \\
\text { change training }\end{array}$} & -2.103 & 0.424 & -1.654 & -1.256 \\
\hline & 0.445 & 0.705 & 0.542 & 0.641 \\
\hline \multirow{2}{*}{ Own radio } & 1.846 & 1.546 & 1.292 & 1.732 \\
\hline & $0.031^{* *}$ & $0.058^{\star *}$ & $0.060^{* *}$ & 0.118 \\
\hline \multirow{2}{*}{ cons } & -5.699 & -7.223 & -0.036 & -5.840 \\
\hline & 0.335 & 0.136 & 0.974 & $0.082^{\star *}$ \\
\hline
\end{tabular}

Base category No adaptation; Number of observations 160; LR chi2(56) 136.36; Log likelihood 175.6034; Prob > chi2 0.0000; Pseudo R-Square 0.3397; Notes: ${ }^{*},{ }^{* *}{ }^{* * *}=$ significant at $10 \%, 5 \%$, and $1 \%$ probability level, respectively.

Thus, the marginal effects from the MNL, which measure the expected change in probability of a particular choice adaptation being made with respect to a unit change in an independent variable, are indicated and discussed (Table 5).

The marginal effect results were considered for interpretation. Table 5 showed the factors that showed the level of significance at $1 \%, 5 \%$, and $10 \%$ respectively are:

Gender of household head: As hypothesized earlier, the gender of the household head is significantly and positively connected with the likelihood of choosing soil and water conservation and cultivating in the wetland by 0.004 and 
Table 5. Marginal effects from the multinomial logit for the choice of adaptation strategies against dry spell.

\begin{tabular}{|c|c|c|c|c|c|c|c|c|c|c|}
\hline \multirow{2}{*}{ Explanatory variable } & \multicolumn{2}{|c|}{$\begin{array}{c}\text { Soil and water } \\
\text { conservation techniques }\end{array}$} & \multicolumn{2}{|c|}{$\begin{array}{c}\text { Diversify multiples } \\
\text { occupation }\end{array}$} & \multicolumn{2}{|c|}{$\begin{array}{l}\text { Changing crop } \\
\text { calendar }\end{array}$} & \multicolumn{2}{|c|}{$\begin{array}{l}\text { Cultivating } \\
\text { in wetland }\end{array}$} & \multicolumn{2}{|c|}{ No adaptation } \\
\hline & $\mathrm{dy} / \mathrm{dx}$ & p-value & $\mathrm{dy} / \mathrm{dx}$ & p-value & $\mathrm{dy} / \mathrm{dx}$ & $\mathrm{p}$-value & $\mathrm{dy} / \mathrm{dx}$ & p-value & $\mathrm{dy} / \mathrm{dx}$ & p-value \\
\hline Gender & 0.1123 & $0.004^{* * *}$ & -0.1297 & $0.051^{* *}$ & -0.0247 & 0.673 & 0.1289 & $0.002^{* * *}$ & -0.0469 & 0.274 \\
\hline Age of HHs & -0.7095 & $0.001^{\star * *}$ & -0.008 & 0.965 & 0.2076 & 0.158 & 0.2099 & 0.240 & 0.3003 & $0.038^{* *}$ \\
\hline Marital status & -0.0443 & 0.657 & 0.1166 & 0.248 & 0.0124 & 0.907 & -0.2076 & 0.107 & 0.1229 & $0.007^{* * *}$ \\
\hline Level-education & 0.0285 & $0.001^{\star \star \star}$ & -0.0140 & $0.004^{\star * \star}$ & 0.0266 & 0.587 & -0.0711 & 0.177 & 0.0419 & $0.010^{\star}$ \\
\hline Years farming & 0.0157 & $0.002^{\star * \star}$ & -0.0028 & 0.527 & -0.0036 & 0.318 & -0.0066 & 0.118 & -0.0028 & 0.321 \\
\hline Household size & 0.0225 & 0.689 & 0.1125 & $0.007^{\star * *}$ & -0.0300 & 0.602 & -0.0789 & 0.209 & -0.0258 & 0.480 \\
\hline Land size & 0.1385 & 0.175 & -0.0228 & 0.836 & -0.0392 & 0.672 & -0.1824 & 0.118 & 0.1059 & 0.195 \\
\hline Area under crop & -0.1278 & 0.239 & -0.0226 & 0.848 & 0.0551 & 0.604 & 0.1972 & $0.001^{* * *}$ & -0.2018 & $0.036^{* *}$ \\
\hline HHs income & -0.0397 & 0.657 & -0.1275 & 0.163 & -0.1145 & 0.251 & 0.0547 & 0.561 & 0.2269 & 0.567 \\
\hline Belong to group & 0.1069 & $0.000^{* * *}$ & 0.0738 & 0.361 & 0.0933 & 0.238 & 0.0492 & 0.531 & -0.2232 & 0.932 \\
\hline Land tenure & 0.0637 & 0.395 & 0.0385 & 0.641 & -0.0298 & 0.730 & -0.2123 & $0.003^{* * *}$ & 0.1399 & $0.002^{* * *}$ \\
\hline Access to credit & -0.2663 & $0.000^{\star * *}$ & 0.0629 & 0.389 & 0.0964 & 0.185 & 0.0267 & 0.712 & 0.1399 & $0.002^{* * *}$ \\
\hline Access extension & 0.2783 & $0.003^{\star * *}$ & -0.0068 & 0.953 & 0.0242 & $0.000^{\star * *}$ & -0.0756 & 0.552 & -0.1717 & $0.024^{* *}$ \\
\hline Acctraincliva & -0.1347 & 0.247 & 0.0796 & 0.482 & -0.0301 & 0.767 & -0.0178 & 0.886 & 0.0673 & 0.560 \\
\hline Own radio & 0.2783 & 0.296 & 0.1548 & $0.006^{\star * *}$ & 0.1027 & $0.001^{\star * *}$ & -0.0895 & 0.137 & -0.0200 & 0.616 \\
\hline
\end{tabular}

Notes: ${ }^{*},{ }^{* *},{ }^{* *}=$ significant at $10 \%, 5 \%$, and $1 \%$ probability level, respectively. Level-Educ (Education level), Areundcro (Area under crop), (Belonging to group), Accredit (Access to credit), Accexten (Access to extension), Acctraincliva (Training on climate variability related topic), and Own radio.

0.002 at $1 \%$ level of significance during dry spell. Male-headed households were $10.9 \%$ associated with the choice of soil and water conservation and cultivation in the wetland at $12.9 \%$ during the dry spell. It is more expected that male-headed households have more likelihood of choosing these strategies than the female because they are labor demanding and require better information. This finding concurs with the argument that male-headed households are more likely to get skills and information about new strategies, unlike female-headed households who have inadequate access to information [26] [27]. While contrary to the above results is negative association of gender with the likelihood of choosing to diversify multiples occupation at 0.051 probability level, this is because the probability of choosing and employing engagement in diversify multiples occupation during dry spell strategies decreases by $12 \%$ since the decision-maker are largely male as reported during the focus group discussion (FGD) that male head household have power over what strategies should the members of the household choose and employed to deal with climatic stress.

Age of the household head: Results in Table 3 showed that age of the household was negatively and significantly associated with the choice of soil and water conservation combine with at $\mathrm{p}<0.001$ level of significance. In this case, a one-unit increase in the age of the household decrease the probability of choosing soil and water conservation, which means that a one-unit increase in the age 
of the household decreases the probability of using soil and water conservation during dry spell by $70.8 \%$ times relative to the base category. On the other hand, the age of the household head shows a positive correlation with the farmers who choose none of the adaptation (No adaptation) at $\mathrm{p}<0.038$. This implies that older farmers are less likely to choose soil and water conservation because they require more labor. The younger households are energized and active than older household to choose soil and water conservation and micro-irrigation as an adaptation strategy to dry spell. This finding is in agreement with [28] who noted that older households' are less likely to choose a single or combination of adaptation strategies compared with the younger household head.

Marital status: The coefficient of marital status was positively and significantly correlated to the probability of the household choosing no adaptation at $\mathrm{p}$ $<0.010$ during the period of a dry spell. This implies that there is an inverse relationship between marital status and farmers' choice of no adaptation to the impact of dry spell. Thus, the marital status of the respondents is not inquisitive about the vagaries of a dry spell while the majority who were, married and not aged is more knowledgeable about climate variability. This suggests that unmarried household heads could have a small household size which could mean less family labor for crop production practices and less engagement in adaptation strategy against the dry spell.

Level of education: Smallholder farmer level of education increases the probability of choosing soil and water conservation to dry spell at $1 \%$ probability level ( $\mathrm{p}<0.001)$. This implied that a unit increase in the level of education would result in a $1.4 \%$ increase in the probability of choosing soil and water conservation against the impact of a dry spell on their farming activities. These results are in agreement with the findings of [28]. Contrary to expectation, the level of education was found to be significant and negatively correlated with the choice of diversify multiples occupation such as engagement in off farm business and mixed farming at $\mathrm{p}<0.001$ level of significant. This meant a unit increase in one level of education would result to a decrease in the choice of diversifying multiples occupation as adaptation strategies during the period of a dry spell. This was contrary to expectation where higher level of education was believed to be positively related to choice of any adaptation strategies. This is because the practices of engaging in diversify multiples occupation as adaptation strategies during dry spell is labour intensive and tedious and this may be the reason why highly educated level households will avoid using them than their less educated counterparts because education also broadens alternative income earning opportunities [29].

Belonging to a group: Involvement of the smallholder farmer in group is positive and significantly at less than $1 \%$ level $(\mathrm{p}<0.000)$ related to choose of soil and water conservation as an adaptation strategy employed by smallholder farmers during dry spell, implying that the probability of choosing soil and water conservation as an adaptation strategy during dry spell is higher for those farmers who have got involved with different farmers groups compared to smallholder farmer who is not a member in any farmers group or doesn't participate 
in such coordinated actions and groups. This reflection as an indication that membership and engagement in farmers groups encourage farmers to engage in a join strategies orientation and learning; farmers involved in farmer field school (FFS) share knowledge and innovation ideas, discuss problems and challenges with others and engage in collaborative decision-making.

Year of farming experience: As expected, experienced farmers in farming have an increased likelihood of using all adaptation strategies. The coefficient of smallholder farmer farming experience was significantly and positively with to the choice of soil and water conservation as adaptation strategies against dry spell at $1 \%$ significant level $(\mathrm{p}<0.002)$. Highly experienced farmers in farming tend to have more information, skills in farming practices and management about dry spell period and are in the position to spread climate variability threat by developing strategic complementarities between activities such as soil and water conservation techniques and crop-livestock diversification. The results of this study reveal that as smallholder farmers advance in years of farming experience increase the choice of soil and water conservation by $1.6 \%$, as an adaptation strategy to dry spell. This result is consistent with finding [30].

The area under crop: The coefficient of an area under crop was positively and significantly correlated with the choice of cultivating in wetland during the dry spell at $1 \%$ significant level $(\mathrm{p}<0.001)$ as shown in Table 3 . Indeed, smallholder farmers who have large are under crop near the swamp are more likely to choose the practices of cultivating in wet land because they have better natural capital than smallholder farmers who have small farm area. Therefore, they can easily invest in wetland cultivation, which demands relatively high investment costs. This result agrees with the findings of [31] which indicates that area under crop positively related to adaptation alternatives, and [32] also find out that area under crop significantly and positively correlated with adaptation. In contrast, marginal the coefficient of an area under crop is negatively but statistically significant at $\mathrm{p}<0.094$ related with no adaptation.

Access to credit: As the marginal coefficient shown in Table 3, access to credit had a negative influence on the probability of choosing soil and water soil conservation at less than $1 \%$ significant level $(\mathrm{p}<0.000)$ as adaptation strategies to dry spell. This implies a marginal increase in access to credit would lead to decrease in the probability of choosing and using soil and water conservation by $26.6 \%$ and positively correlated to the choice of no adaptation at $1 \%$ significant level ( $\mathrm{p}<0.001$ ). The negative sign shows that smallholder farmers get the credit and use it for his or her household subsistence need while not investing in productive strategies against the impact of dry spell however this does not agree with the innovation theory [33].

Access to extension service: Results of the multinomial logit models shows that access to extension amenities has positive and significant association with the probability of choosing soil and water conservation at $\mathrm{p}<0.003$ and changing crop calendar at $\mathrm{p}<0.003$ level of significance. This indicates that a one-unit increase in the extension contact is likely to increase the likelihood of the small- 
holder farmer choosing and adapting soil and water conservation and changing cropping calendar category as adaptation strategies to dry spell by $27.8 \%$ and $24.2 \%$ higher than those households' who do not have access to extension services. Smallholder farmers who have regular access to extension services are more likely to be informed of the expected dry spell period. This result concurs with many researchers; [34] who find out that farmers who obtain information through extension workers are more likely to be aware of the changes in climatic pattern and choice adaptation strategies in order to deal with such stress.

Own Radio: As hypothesized earlier, having a radio by smallholder farmers has a positive and significant influence on the choice of engagement in diversifying multiples occupation at $\mathrm{p}<0.006 \%$ and changing of crop calendar at $\mathrm{p}<$ 0.001 . Ownership of radio has the likelihood of increasing the probability of choosing to diversify multiples occupation category such as off-farm business and mixed farming adaptation strategies and changing crop calendar during dry spell by $15.5 \%$ and $10.3 \%$ respectively. Households with access to radio are privilege to lots of information on how to deal with dry spell. This suggests that dry spell awareness campaign on radio and other media channels is an effective way of providing information to smallholder farmers on how to prepare and cope during the period of dry spell occurrence by engaging in practices of diversifying multiples occupation. Radio such as Baaba FM in Jinja and Eye FM were mentioned during the focus group discussion (FGDs) to provide information and campaign on the expected period of the dry spell in the area.

\section{Conclusions}

Adaptation strategies used by the majority of the household's respondents included soil and water conservation, mixed farming, engaging in off-farm activities, use of mulching, use of manure, growing of food security crop and changing planting date. Other common adaptation strategies included crop water harvesting techniques, early planting, inter-cropping, and crop rotation, cultivating in wetland and rearing livestock. Adaptation strategies like change crop calendar with respect to the stress and use of drought-tolerant crops have low adoption rates in the area. However, in some cases, the farmers opt for such strategies owing to the fact that they have limited access to resources and choices because of socioeconomic factors.

Through the use of these adaptation strategies farmers manage to increase their resilience to climate variability related stresses but there is still a need to improve household adaptation level through strengthening the farmers' adaptation coping strategies because smallholder farmers believed that climate variability was a major cause of declining yields and increase in the crop pest and disease incident, reduction in quantity and water quality and, food shortage during certain period of the year, high risk of crop damage as a consequence of flood and dry spell in the study area. In general, based on the respondents around 99\% of the smallholder farmers have taken at least one or combination of adaptation strategies in response to climate variability impact on their farming activities. 
Study finding showed that several factors significantly influenced the choice of dry spell-induced adaptation strategies. These were the gender of the household, the age of household, household size, years of farming experience, access to credit, household income, membership of group or associations, access to extension services, the size of area under crop and ownership of radio.

\section{Recommendations}

Based on the findings and results of the study, the following recommendations are suggested to lessen the diverse impacts of climate variability on farming system and rural livelihood of smallholder farmers in Namutumba district.

1) Strengthening smallholder farmers existing water and soil conservation and expand the area cultivated with irrigation schemes. In addition, government and NGOs programmes need to build on existing knowledge and adaptation strategies in order to ensure sustainability of their activities.

2) Policymakers should focus at enhancing smallholder farmers' household characteristics by reviewing farmer extension so as to come up with devising a package that is tailored to the perceived actual needs of smallholder farmers and designing farm management adoption programmes based on the farmers household characteristic, such as years of schooling, gender, and membership to social groups.

3) Given the high degree of uncertainty about how climate variability affects smallholder farmers in the area, government policy intervention in the state should focus primarily on strengthen the capacity of smallholder farmers and institutions for identifying and assessing climate variability through programmes to educate and inform smallholder farmers and other relevant stakeholders on climate variability and their potential impacts on farmers' farming activities.

4) Government future policies and Non-Governmental organization programme should also be able to strengthen the ability of smallholder farmers and local institutions in the area by determining and coordinated efforts through programme that educate them on climate variability and their potential impacts on smallholder farmers' farming activities while gearing towards increasing smallholder farmers' access to weather forecasts as a strategy to increase awareness and therefore preparedness for drought and flood occurrences, among other climate variability related shocks. Additionally, policy interventions that encourage informal social networks i.e. farmer to farmer extension services can promote group discussions. This is very necessary for smallholder farmers to share experience, information, and knowledge among them. Therefore, policy option which is intended for reducing the climate variability related difficulties should also focus on accessing improved inputs such as better seeds, and micro-irrigation equipment's to smallholder farmers at a fair price.

\section{Acknowledgements}

The authors gratefully acknowledge the financial support provided by the Regional Capacity building for Sustainable Natural Resource Management \& 
Agricultural Productivity under climate change project (CAPSNAC) funded by NORED. Furthermore, we are thankful to the enumerators for translating the questions into local languages and for participating in the survey.

\section{Conflicts of Interest}

The authors declare no conflicts of interest regarding the publication of this paper.

\section{References}

[1] Puddester, D. (2014) Managing and Mitigating Fatigue in the Era of Changing Resident Duty Hours. BMC Medical Education, 14, S3. https://doi.org/10.1186/1472-6920-14-S1-S3

[2] Adger, W.N. and Vincent, K. (2005) Uncertainty in Adaptive Capacity. IPCC Special Issue on Describing Uncertainties in Climate Change to Support Analysis of Risk and Options. Comptes Rendus Geoscience, 337, 399-410. https://doi.org/10.1016/j.crte.2004.11.004

[3] Mwaura, F.M. and Okoboi, G. (2014) Climate Variability and Crop Production in Uganda. Journal of Sustainable Development, 7, 159-172. https://doi.org/10.5539/jsd.v7n2p159

[4] Adhikari, U., Nejadhashemi, A.P. and Woznicki, S.A. (2015) Climate Change and Eastern Africa: A Review of Impact on Major Crops. Food and Energy Security, 4, 110-132. https://doi.org/10.1002/fes3.61

[5] Müller, C., Cramer, W., Hare, W.L. and Lotze-Campen, H. (2011) Climate Change Risks for African Agriculture. Proceedings of the National Academy of Sciences of the United States of America, 108, 4313-4315. https://doi.org/10.1073/pnas.1015078108

[6] Bashaasha, B., Thomas, T., Waithaka, M. and Kyotalimye, M. (2012) East African Agriculture and Climate Change: Uganda. Research Summaries. International Food Policy Research Institute, Washington DC. http://hdl.handle.net/10568/34913

[7] NEMA (2007) State of Environment Report for Uganda, NEMA. Kampala.

[8] Wasige, J.E. (2009) Assessment of the Impact of Climate Change and Climate Variability on Crop Production in Uganda: End of Project Report.

[9] Okonya, J.S., Syndikus, K. and Kroschel, J. (2013) Farmers' Perception of and Coping Strategies to Climate Change: Evidence from Six Agro-Ecological Zones of Uganda. Journal of Agricultural Science, 5, 252-263. https://doi.org/10.5539/jas.v5n8p252

[10] Tiyo, C.E. and Edroma, E.L. (2015) Understanding Small-Scale Farmers' Perception and Adaption Strategies to Climate Change Impacts: Evidence from Two Agro-Ecological Zones Bordering National Parks of Uganda. Journal of Agricultural Science, 7, 253-270.

[11] Helgeson, J.F., Dietz, S. and Hochrainer-Stigler, S. (2013) Vulnerability to Weather Disasters: The Choice of Coping Strategies in Rural Uganda. Journal of Ecology and Society, 18, 1-23. https://doi.org/10.5751/ES-05390-180202

[12] Kothari, C.R. (2004) Research Methodology, Method and Techniques. 2nd Edition, New Delhi: New Age International Limited. http://www.worldcat.org/title/research-methodology-methods-techniques/oclc/395 $\underline{725716}$ 
[13] Environmental Alert (2010) Climate Change in Uganda: Insights for Long Term Adaptation and Building Community Resilience. https://www.slideshare.net/JoshuaZake1/climate-change-issues-paper

[14] UBOS (2009) The State of Uganda Population Report 2009: Adressing the Effects of Climate Change on Migration Patterns and Women. Kampala.

[15] Woldenhanna, T. and Oskam, A. (2001) Income Diversification and Entry Barriers: Evidence from the Tigray Region of Northern Ethiopia. Journal of Food Policy, 26, 351-365. https://doi.org/10.1016/S0306-9192(01)00009-4

[16] Greene, W.H. (2012) Econometric Analysis. 7th Edition, Pearson Education, Inc., New York.

https://www.pearson.com/us/higher-education/program/Greene-Econometric-Anal ysis-8th-Edition/PGM334862.html

[17] Nhemachena, C. and Hassan, R. (2008) Determinants of African Farmers' Strategies for Adapting to Climate Change: Multinomial Choice Analysis. African Journal of Agricultural and Resource Economics, 2, 83-104.

[18] Wooldridge, J.M. (2001) Econometric Analysis of Cross Section and Panel Data. MIT Press, Cambridge, London.

[19] Hess, S. and Train, K. (2017) Correlation and Scale in Mixed Logit Models. Journal of Choice Modelling, 23, 1-8. https://doi.org/10.1016/j.jocm.2017.03.001

[20] Deressa, T., Hassan, R.M., Alemu, T., Yesuf, M. and Ringler, C. (2008) Analyzing the Determinants of Farmers' Choice of Adaptation Methods and Perceptions of Climate Change in the Nile Basin of Ethiopia. No. IFPRI Discussion Paper 00798. http://ebrary.ifpri.org/cdm/ref/collection/p15738coll2/id/1385

[21] Xhafaj, E. and Nurja, I. (2015) The Principal Components Analysis and Cluster Analysis as Tools for the Estimation of Poverty, an Albanian Case Study. International Journal of Science and Research, 4, 2013-2016.

[22] Westengen, O.T., Jeppson, S. and Guarino, L. (2013) Global Ex-Situ Crop Diversity Conservation and the Svalbard Global Seed Vault: Assessing the Current Status. PLOS ONE, 8, e64146.

[23] Zizinga, A., Kangalawe, R., Ainslie, A., Tenywa, M., Majaliwa, J., Saronga, N. and Amoako, E. (2017) Analysis of Farmer's Choices for Climate Change Adaptation Practices in South-Western Uganda, 1980-2009. Journal of MDPI Climate, 5, 89. https://doi.org/10.3390/cli5040089

[24] Bagamba, F., Bashaasha, B., Claessens, L. and Antle, J. (2012) Assessing Climate Change Impacts and Adaptation Strategies for Smallholder Agricultural Systems in Uganda. African Crop Science, 20, 303-316.

[25] Shikuku, K.M., Winowiecki, L., Twyman, J., Eitzinger, A., Perez, J.G., Mwongera, C. and Läderach, P. (2017) Smallholder Farmers' Attitudes and Determinants of Adaptation to Climate Risks in East Africa. Climate Risk Management, 16, 234-245. https://doi.org/10.1016/j.crm.2017.03.001

[26] Temesgen, D., Hassan, R.M., Ringler, C., Alemu, T. and Yesuf, M. (2009) Determinants of Farmers' Choice of Adaptation Methods to Climate Change in the Nile Basin of Ethiopia. Global Environmental Change, 19, 248-255. https://doi.org/10.1016/j.gloenvcha.2009.01.002

[27] Obayelu, O.A., Adepoju, A.O. and IDowu, T. (2014) Factors Influencing Farmers' Choices of Adaptation to Climate Change in Ekiti State, Nigeria. Journal of Agriculture and Environment for International Development, 108, 3-16.

[28] Maddison, D. (2006) The Perception of and Adaptation to Climate Change in Afri- 
ca. Policy Research Working Paper No. 4308, World Bank, Washington DC, 1-47.

[29] Kansiime, M.K., Wambugu, S.K. and Chris, A. (2014) Determinants of Farmers' Decisions to Adopt Adaptation Technologies in Eastern Uganda. Journal of Economics and Sustainable Development, 5, 189-199. http://www.iiste.org

[30] Bazezew, A., Bewket, W. and Nicolau, M. (2013) Rural Households' Livelihood Assets, Strategies and Outcomes in Drought-Prone Areas of the Amhara Region, Ethiopia: Case Study in Lay Gaint District. African Journal of Agricultural Research, 8, 5716-5727.

[31] Ringler, C., Hassan, R.M. and Deressa, T.T. (2011) Perception of and Adaptation to Climate Change by Farmers in the Nile Basin of Ethiopia. The Journal of Agricul tural Science, 149, 23-31. https://doi.org/10.1017/S0021859610000687

[32] Gbetibouo, G.A. (2009) Understanding Farmers' Perceptions and Adaptations to Climate Change and Variability: The Case of the Limpopo Basin, South Africa. IFPRI Discussion Paper 00849, 52.

[33] Aizstrauta, D., Ginters, E. and Eroles, M.A.P. (2015) Applying Theory of Diffusion of Innovations to Evaluate Technology Acceptance and Sustainability. Procedia Computer Science, 43, 69-77. https://doi.org/10.1016/j.procs.2014.12.010

[34] Hassan, R., Nhemachena, C., Hassan, R., Nhemachena, C. and Rashid, H. (2008) Determinants of African Farmers' Strategies for Adapting to Climate Change: Multinomial Choice Analysis. African Journal of Agricultural and Resource Economics, 2, 83-104. 